\title{
Eighteen years of GPS surveys in the Aeolian Islands (southern Italy): open data archive and velocity field
}

\author{
Alessandra Esposito ${ }^{1}$, Grazia Pietrantonio ${ }^{1}$, Valentina Bruno ${ }^{2}$, Marco Anzidei ${ }^{1,{ }^{\star}}$, \\ Alessandro Bonforte ${ }^{2}$, Francesco Guglielmino ${ }^{2}$, Mario Mattia ${ }^{2}$, Giuseppe Puglisi ${ }^{2}$, \\ Vincenzo Sepe ${ }^{1}$, Enrico Serpelloni ${ }^{1}$ \\ ${ }^{1}$ Istituto Nazionale di Geofisica e Vulcanologia, Centro Nazionale Terremoti, Rome, Italy \\ ${ }^{2}$ Istituto Nazionale di Geofisica e Vulcanologia, Sezione di Catania, Osservatorio Etneo, Catania, Italy
}

\author{
Article history \\ Received July 2, 2015; accepted July 14, 2015. \\ Subject classification: \\ GPS open data archive, GPS networks, GPS velocity field, Aeolian Islands.
}

\begin{abstract}
Since the early 1970s, geodetic networks became a most important tool to monitor the present day deformations of the volcanic arc of the Aeolian Islands. The first benchmarks were installed in this region at Lipari and Vulcano Islands and the number of GPS benchmarks increased in time since the early '90s. These networks were periodically surveyed in the frame of national and international geodynamic projects and for Civil Protection programs devoted to the mitigation of the volcanic hazard. The Istituto Nazionale di Geofisica e Vulcanologia (INGV) played a fundamental role in the realization and periodical reoccupation of these networks, with the goal to investigate the tectonic and volcanic processes, still active in this crucial area of the central Mediterranean. An updated GPS velocity map for this region, both for the horizontal and vertical component of land motion, with details for Lipari, Vulcano and Panarea Islands, is provided in this paper. The presented GPS velocity field also includes a set of additional discrete stations located in northern Sicily and Calabria together with data from the available CGPS networks active in southern Italy. Here we show the results from eighteen years of repeated GPS surveys performed in this region in the time span 1995-2013 and the open access AINET-GPS data archive, now freely available for the scientific community. Data will support scientific research and hopefully improve the assessment of volcanic and seismic hazard in this region.
\end{abstract}

\section{Introduction}

GPS surveys represent a key tool to investigate geodynamic processes at the Earth's surface and estimate volcanic and seismic strain in active areas, such as along faults or signals from magmatic injections at surface, occurring inside volcanic reservoirs [Dvorak and Dzurisin 1997, Anzidei et al. 1998, Anzidei et al. 2001, Anzidei et al. 2005, Serpelloni et al. 2005, Serpelloni et al. 2006, Anzidei et al. 2008, Tregoning and Rizos 2008, Esposito et al. 2010, Patanè et al. 2013, De Martino et al. 2014,
Ferranti et at. 2014, Baldi et al. 2015]. Surveys style GPS networks set up in Italy during the last decades, now have a crucial role to densify the current CGPS networks, thus better constraining the velocity field solutions and related strain maps, especially during seismic cycle and hydrothermal volcanic systems [Anzidei et al. 2009, Devoti et al. 2012, Galvani et al. 2012].

The first pioneering GPS campaigns started in southern Italy in 1987 in the frame of the Wegener/Medlas-Calabrian Arc international projects [Kaniuth et al. 1989]. Although these were experimental in nature, they put the basis for the realization of the first regional geodetic networks for geophysical applications devoted to detect the current deformations rates in this active area of the Mediterranean basin which is placed across the African and Eurasian tectonic plates [Achilli et al. 1993, Anzidei et al. 1995]. Since then have been established more GPS survey style and continuous CGPS networks in Italy and surrounding regions for geodynamics, surveying and engineering applications, providing valuable additional data to detect the ongoing deformation pattern of this area at different scales [Selvaggi et al. 2006, Avallone et al. 2010, Devoti et al. 2014, Devoti et al. 2015]. During the last decade, GPS data provided new insights on the current kinematics and geodynamic transition across this plate boundary, with details on tectonic trends and volcanic unrest [Bonaccorso 2002, Hollenstein et al. 2003, Mattia et al. 2008, Esposito et al. 2010, Barreca et al. 2014].

We focus on the Aeolian volcanic arc, which is a key geodynamic region of the central Mediterranean basin and consists in the seven volcanic islands of Alicudi, Filicudi, Salina, Lipari, Vulcano, Panarea and Stromboli 


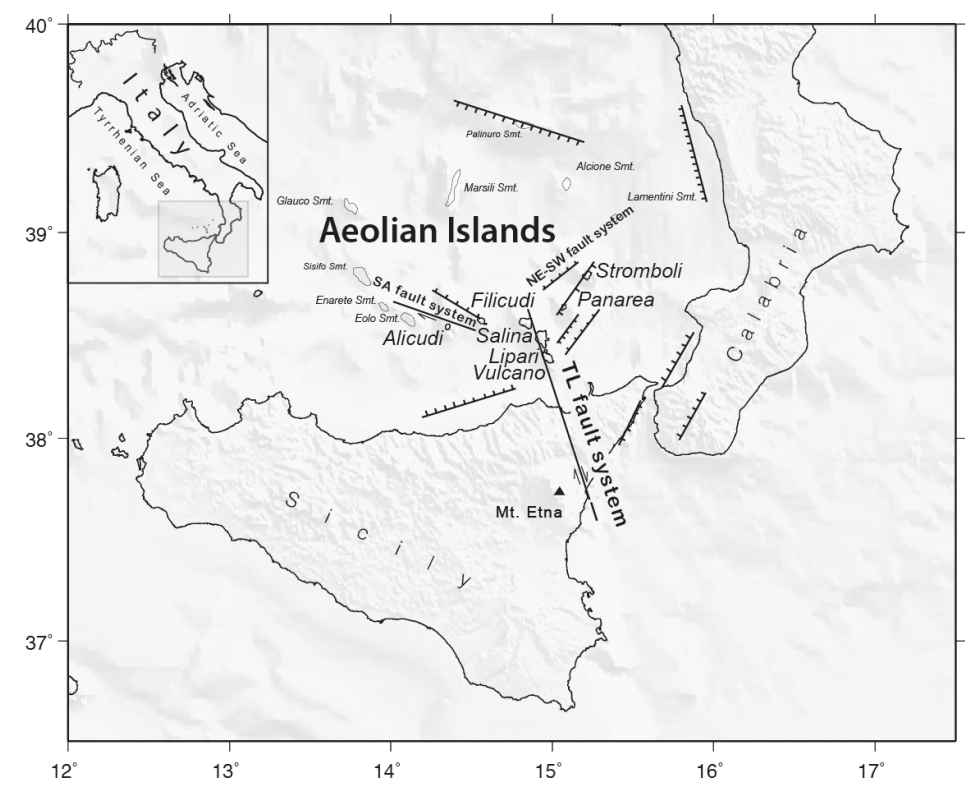

Figure 1. Tectonic setting of the Aeolian Islands.

and some minor islets and seamounts. This region is crucial to understand the transition processes from oceanic subduction to continental collision and backarc extensional basin formation in the general context of Africa-Eurasia convergence that characterizes the Mediterranean area [Malinverno and Ryan 1986, Faccenna et al. 2001]. These islands, which are lying in an area extending for about $80 \mathrm{~km} \mathrm{E-W}$ and $60 \mathrm{~km} \mathrm{~N}-\mathrm{S}$, along the margin of the southern Tyrrhenian Sea, close to the Calabrian-Peloritan mountain chain to the east and the abyssal Marsili basin to the west [Barberi et al. 1973, Beccaluva et al. 1985], fall within the back-arc Tyrrhenian basin. The latter is related to the NW-directed subduction of the Ionian slab below Calabria (Figure 1). This region is characterized by intermediate and deep seismicity that fairly well identify the WadatiBenioff zone beneath the Calabrian arc [Neri et al. 2003, Chiarabba et al. 2008]. The Aeolian volcanic arc can be divided into (i) a central portion (Vulcano, Lipari and Salina Islands), about NW oriented; (ii) an eastern arc (Stromboli and Panerea Islands), NE-SW trending, and (iii) a western arc (Alicudi and Filicudi Islands), WSW-ESE trending (Figure 1). Volcanism started between 1.3 Ma in the western arc and from 0.8 $\mathrm{Ma}$ to present in the eastern-central arc [De Astis et al. 2003, and references therein], with documented coeval unrests, such as in 2002-2003 (degassing at Panarea and effusive eruption at Stromboli).

Geodetic data discussed in the last years for the central Mediterranean and southern Italy have been crucial to outline the central Aeolian Islands as the area of transition between the active N-S compression in the northwestern part of the archipelago and the NW-SE trending extension in the eastern part of Aeolian arc, eastern Sicily and Calabria [Anzidei et al. 2001, Hollenstein et al. 2003, D’Agostino and Selvaggi 2004, Serpelloni et al. 2005, Serpelloni et al. 2007, Mattia et al. 2008, Devoti et al. 2010, Serpelloni et al. 2010, Devoti et al. 2011, Barreca et al. 2014, Mastrolembo Ventura et al. 2014]. In particular, the transition from compressional to extensional regime occurs through an area with transtensional deformation along the NNW-trending Tindari-Letojanni fault system, across the central Aeolian Islands [Pondrelli et al. 2004, Argnani et al. 2007, Esposito et al. 2010, Serpelloni et al. 2010].

In this paper we provide, for the first time, an open data archive available to the scientific community. Our archive contains GPS data collected during repeated surveys for a timespan 18 years long between 1995 and 2013. RINEX data and metadata (station log files), collected on 28 benchmarks of the survey style GPS networks operating in this area can be retrieved via ftp. The analysis of the GPS data and estimates of the coordinate time series and site velocities in a fixed reference frame relative to a Eurasia are presented. Finally, an updated horizontal and vertical GPS velocity field derived from the joint analysis of GPS and CGPS networks for this region, is shown.

\section{GPS networks and campaigns}

The first geodetic monitoring in the Aeolian Islands was implemented across the Lipari-Vulcano volcanic system in the early ' 70 s of the past century [Bonaccorso 2002, Alparone et al. 2014]. At the beginning this network was surveyed by terrestrial techniques using optical instruments (theodolites) or EDM (Electro-optical Distance Meters) and only after the end of the ' 80 s by GPS. The beginning of the first experi- 
mental regional GPS campaigns in the Aeolian Islands is marked by The Wegener/Medlas-Calabrian Arc project in 1987, using single frequency GPS receivers [Kaniuth et al. 1989].

Further regional campaigns were performed with this equipment until 1990, using different brand of receivers. These first surveys were considered experimental in nature because the GPS system was still in progress and not yet fully operational and data were mainly used to understand and check the validity of GPS for geodynamic applications in the Mediterranean region [Achilli et al. 1993, Anzidei et al. 1995]. These former data suffered from a still too poor satellite constellation (sometimes less than four were simultaneously observed, preventing the collection of valid geodetic data), the use of single frequency receivers (L1 carrier) and too short daily sessions of observation duration (4 to 8 hours).

Later, after the improvement of the GPS satellite constellation and the implementation of the new L2 carrier, this space based geodetic technique become to provide robust data for geodesy and geophysics. Therefore, the number of the geodetic benchmarks increased dramatically thanks to the realization of new local densely distributed networks. Presently, 28 geodetic benchmarks have been established across the Aeolian Islands: 6 of these are located at Lipari, 9 at Vulcano and 9 at Panarea, while the remaining are placed at Alicudi, Filicudi, Salina and Stromboli Islands.

The former benchmarks of the EDM networks were upgraded and then re-occupied using GPS receivers and included in the new networks. In particular, the two networks named "Lipari-Vulcano" and "Vulcano North" where fully converted to GPS since 1996 [Bonaccorso 2002]. Meanwhile, in 1995 started the realization of a new network of continuous monitoring GPS stations (CGPS) by the former Istituto Internazionale di Vulcanologia (that in 2001 was included in the Istituto Nazionale di Geofisica e Vulcanologia INGV) and in 2001 by INGV [Anzidei et al. 2004]. In the following years this network was developed and now consists in 7 operational GPS stations located in the Lipari-Vulcano area. Additional CGPS stations have been deployed in time in the remaining islands ( 1 in Alicudi, 1 in Filicudi, 3 in Panarea, 4 in Stromboli and 2 in Salina). Therefore, the spatial distribution and typology of the GPS and CGPS benchmarks and stations in the Aeolian Islands is not homogeneous due to the different history of these networks, the aims that driven the realization of the individual benchmarks and stations and the timing of their installation (see Bonforte and Guglielmino [2008], for the history of the network at Lipari and Vulcano). These discrete networks can be classified from the typologies of their benchmarks, site location and antenna mount set up, as shown in Tables 1 and 2 and Figure 2, besides the monuments of the continuous monitoring CGPS stations. Further details are reported in Anzidei et al. [1995], Anzidei and Esposito [2003], Bonforte and Guglielmino [2008], Bonaccorso et al. [2010], Pesci et al. [2013], Surace [1997] and Kaniuth et al. [1989].

We recall here that the geodetic networks in this region have been installed in time for geodynamics applications or to monitor volcanic activity, especially during volcanic crisis, like at Panarea, Lipari, Vulcano and Stromboli. Therefore the realization of the individual benchmarks was driven by technical or scientific goals. Because the GPS technique does not require the intervisibility between observation points, some benchmarks formerly located in uncomfortable and remote places (such as the top of hills) have been replaced with new benchmarks of easier access to facilitate GPS surveys [Bonforte and Guglielmino 2008].

\section{GPS data}

Although the early GPS campaigns in the Aeolian Islands started in 1987, we have considered as valid data suitable for geodynamic applications only those collected in time span 1995-2013. These were acquired in the frame of research and monitoring projects such as the Wegener/Medlas - Calabrian Arc [Kaniuth et al. 1989], Tyrgeonet [Achilli et al. 1993, Anzidei et al. 1995,
Type of benchmark location
Type of benchmark

3D (iron made)

Hungarian (bronze made)

IGM marker

Spike (iron made)

Pillars with thread on top
Antenna set up mode constrained 3D INGV type

constrained 3D Hungarian type

Tripod, Wild base, 2D IGM type

Tripod, Wild base, 2D IGM type

constrained 2D IGM type

Wild base

Table 1. Type of benchmark location, type of benchmark and mode of antenna set up used for the GPS discrete networks in the Aeolian Islands. 


\begin{tabular}{|c|c|c|c|c|c|c|c|c|c|c|c|c|c|c|}
\hline Island & $\begin{array}{l}\text { Station } \\
\text { ID }\end{array}$ & Lon & Lat & $\begin{array}{l}\mathrm{Ht} \\
(\mathrm{m})\end{array}$ & $\begin{array}{l}\mathrm{v} \text { East } \\
\mathrm{mm} / \mathrm{yr}\end{array}$ & $\begin{array}{c}\sigma \mathrm{vE} \\
\mathrm{mm} / \mathrm{yr}\end{array}$ & $\begin{array}{l}\text { v North } \\
\mathrm{mm} / \mathrm{yr}\end{array}$ & $\begin{array}{c}\sigma \mathrm{vN} \\
\mathrm{mm} / \mathrm{yr}\end{array}$ & $\begin{array}{l}\mathrm{v} U \mathrm{p} \\
\mathrm{mm} / \mathrm{yr}\end{array}$ & $\begin{array}{c}\sigma \mathrm{vUp} \\
\mathrm{mm} / \mathrm{yr}\end{array}$ & $\begin{array}{l}\text { Benchmark type and } \\
\text { antenna set up }\end{array}$ & $\begin{array}{c}\text { Date of } \\
\text { construction }\end{array}$ & $\begin{array}{c}\text { time } \\
\text { span (years) }\end{array}$ & $\begin{array}{l}\text { additional } \\
\text { data }\end{array}$ \\
\hline Alicudi & $A L C D$ & 14.356 & 38.531 & 51.1 & -1.2 & 0.1 & 4.5 & 0.1 & -1.2 & 0.4 & $3 \mathrm{DB}, 3 \mathrm{D}$ & 1996 & $1996-2013$ & \\
\hline Filicudi & FILI & 14.578 & 38.563 & 173.2 & 0.8 & 0.3 & 3.5 & 0.3 & -2.9 & 1.1 & 3DB, 3D & 1996 & $1996-2013$ & \\
\hline \multirow[t]{6}{*}{ Lipari } & LCAP & 14.954 & 38.444 & 228.7 & -3.6 & 1.1 & 5.4 & 0.8 & -7.4 & 3.3 & P,TH & 1974 & 1996-2009 & \\
\hline & LFAL & 14.945 & 38.444 & 256.1 & -0.1 & 0.6 & 5.4 & 0.6 & -7.0 & 2.6 & $\mathrm{P}, \mathrm{TH}$ & 1974 & 1996-2009 & \\
\hline & LGUA & 14.946 & 38.455 & 409.3 & -1.1 & 0.6 & 5.1 & 0.6 & -10.0 & 2.1 & $\mathrm{P}, \mathrm{TH}$ & 1974 & 1996-2009 & \\
\hline & LMAZ & 14.906 & 38.483 & 366.4 & 1.1 & 0.5 & 3.9 & 0.5 & -11.6 & 1.9 & $\mathrm{P}, \mathrm{TH}$ & 1974 & 1996-2009 & \\
\hline & LROS & 14.977 & 38.483 & 282.1 & -3.9 & 0.6 & 3.4 & 0.6 & -5.5 & 2.4 & $\mathrm{P}, \mathrm{TH}$ & 1974 & $1996-2009$ & \\
\hline & LSAN & 14.934 & 38.485 & 580.2 & 0.1 & 0.6 & 3.7 & 0.6 & -11.8 & 2.0 & $\mathrm{P}, \mathrm{TH}$ & 1974 & 1996-2009 & \\
\hline \multirow[t]{4}{*}{ Panarea } & PA3D & 15.074 & 38.633 & 145.4 & -1.3 & 0.1 & 2.0 & 0.1 & 2.8 & 0.6 & $3 \mathrm{DB}, 3 \mathrm{D}$ & 2003 & $2003-2013$ & \\
\hline & PANA & 15.074 & 38.633 & 145.1 & -1.3 & 0.3 & 2.0 & 0.5 & 2.8 & 0.9 & S, Trip & 1987 & $1996-2013$ & 1995 \\
\hline & PC3D & 15.064 & 38.639 & 462.9 & 0.2 & 0.4 & 1.4 & 0.6 & -7.7 & 1.3 & $3 \mathrm{DB}, 3 \mathrm{D}$ & 2013 & 2013 & \\
\hline & PCOR & 15.064 & 38.639 & 465.3 & 0.2 & 0.4 & 1.4 & 0.7 & -7.7 & 2.2 & IGM MR, Trip & 1970 & 2003-2013 & \\
\hline Basiluzzo & BA3D & 15.116 & 38.662 & 96.4 & -2.2 & 1.6 & 0.8 & 1.7 & -7.0 & 6.9 & $3 \mathrm{DB}, 3 \mathrm{D}$ & 2003 & 2003-2013 & \\
\hline Bottaro & вотт & 15.111 & 38.638 & 54 & -1.7 & 0.2 & 2.8 & 0.2 & -5.2 & 0.9 & $3 \mathrm{DB}, 3 \mathrm{D}$ & 2003 & 2003-2006 & \\
\hline Lisca Bianca & LIBI & 15.113 & 38.639 & 75.5 & -2.2 & 1.7 & 5.1 & 0.9 & 0.0 & 4.2 & IGM MR, BS or Trip & 2003 & 2003-2013 & 1997 \\
\hline Lisca Nera & LINE & 15.107 & 38.635 & 46.9 & -1.4 & 0.3 & 2.7 & 0.3 & -4.1 & 1.2 & 3DB, 3D & 2003 & 2003-2013 & \\
\hline Panarelli & PNRL & 15.100 & 38.642 & 47.3 & -1.3 & 0.4 & 2.8 & 0.8 & -3.5 & 1.5 & $3 \mathrm{DB}, 3 \mathrm{D}$ & 2003 & 2003-2013 & \\
\hline Salina & SALI & 14.872 & 38.559 & 62.7 & 1.5 & 0.1 & 1.7 & 0.2 & -3.6 & 0.4 & 3DB, 3D & 1996 & 1996-2013 & 1995 \\
\hline Stromboli & STRO & 15.242 & 38.801 & 50 & 0.5 & 0.4 & 2.9 & 0.7 & 0.1 & 1.3 & S, W or IGM BS & 1987 & 1996-2005 & 1994 \\
\hline \multirow[t]{9}{*}{ Vulcano } & VCRA & 14.965 & 38.403 & 435.2 & -0.5 & 1.6 & 10.8 & 2.8 & -7.7 & 5.8 & $\mathrm{P}, \mathrm{TH}$ & 1974 & 1996-2009 & \\
\hline & VLEN & 14.946 & 38.408 & 231.2 & 0.7 & 0.6 & 8.8 & 0.9 & -8.0 & 1.9 & $\mathrm{P}, \mathrm{TH}$ & 1974 & 1996-2009 & \\
\hline & VMOL & 14.986 & 38.396 & 424.1 & -1.0 & 0.9 & 8.9 & 1.2 & -5.8 & 2.6 & $\mathrm{P}, \mathrm{TH}$ & 1974 & 1996-2009 & \\
\hline & VPLI & 14.956 & 38.430 & 68.6 & -0.4 & 0.9 & 6.6 & 1.5 & -10.6 & 3.2 & $\mathrm{P}, \mathrm{TH}$ & 1974 & 1996-2009 & \\
\hline & VROS & 14.974 & 38.395 & 369.1 & 0.6 & 1.1 & 9.0 & 2.1 & -6.8 & 4.2 & $\mathrm{P}, \mathrm{TH}$ & 1974 & $1996-2009$ & \\
\hline & VSAR & 14.961 & 38.390 & 525.7 & -1.3 & 1.1 & 9.8 & 1.6 & -7.5 & 3.2 & $\mathrm{P}, \mathrm{TH}$ & 1974 & 1996-2009 & \\
\hline & VSER & 14.985 & 38.378 & 513.5 & -1.3 & 0.4 & 8.2 & 0.8 & -2.3 & 1.7 & IGM P, IGM BS \& TH & 1970 & 1996-2009 & 1995 \\
\hline & VUCA & 14.952 & 38.417 & 50.6 & 0.1 & 0.6 & 7.0 & 1.0 & -5.8 & 2.0 & 3DB, 3DM & 1996 & 1996-2009 & \\
\hline & VVUL & 14.963 & 38.426 & 152.4 & -0.4 & 0.9 & 6.1 & 1.0 & -9.7 & 2.3 & $\mathrm{P}, \mathrm{TH}$ & 1974 & $1996-2009$ & \\
\hline
\end{tabular}

Table 2. Velocities and uncertainties (in $\mathrm{mm} / \mathrm{yr}^{-1}$ ) of the GPS benchmarks. Station name and ID; coordinates; ITRF2008 velocities with respect to Eurasia at $1 \sigma$ confidence level; benchmark type and antenna set up mode; date of construction of the benchmark; time span of GPS data reported in the open access archive; additional GPS data. See text for further details.

Anzidei et al. 2001], Department of Civil Protection [Esposito et al. 2010] and other monitoring programs [Mattia et al. 2008, Alparone et al. 2014]. Occupation duration was typically performed during about five to seven days for each campaign, providing corresponding observation data files. Surveys were repeated about yearly of every two or three years, but with more frequent reoccupations of the geodetic benchmarks during volcanic crisis.

The AINET-GPS open data archive (Aeolian Islands NETwork - Global Positioning System) is organized in 18 main folders and 275 subfolders, containing 1353 file of observations data collected at 30 seconds sampling rate at the benchmarks of the GPS networks located in the Aeolian Islands. In addition are included CGPS data for a set of continuous monitoring, stations consisting in 9160 file, organized in 2963 folders. Raw data are stored into the Receiver Independent Exchange format (RINEX) and compressed in the Hatanaka format. Data can be retrieved via anonymous FTP from the following link: ftp:/ / ftp.ingv.it/ pub/ainet-gpsdata. Data quality has been tested before archiving using TEQC software (www.unavco.org) and files with poor observation quality were discarded.

The archive contains also some auxiliary files and metadata (logs and station info files) to detail the employed instruments and antenna heights (the latter always re- ferred to the top of the benchmark, that represents the reference plane) at each benchmark for the individual campaigns.

\section{GPS data analysis and velocity field estimation}

The GPS data analysis follows a procedure that can be summarized in 3 main steps: (i) daily processing of the GPS networks; (ii) combination of daily solutions and (iii) definition of the reference frame, time series analysis and velocity field estimation.

\subsection{Daily processing of the Aeolian GPS network}

The analyzed dataset consists in GPS data collected in the time span 1996-2013 on 28 survey-style benchmarks located in the area of Aeolian Islands (Table 2), together with additional GPS and CGPS data from stations located in southern Italy. We also included in our analysis 9 European IGS sites, used as "anchor" stations to combine the obtained daily solutions with those of a globally distributed network of IGS stations, which is a preliminary step for the transformation into the ITRF2008 reference frame.

We process data using the Bernese GNSS software 5.0 [Dach et al. 2007], following the EUREF Guidelines for EPN Analysis Centers (http:/ / www.epncb.oma.be/ _documentation/guidelines/).

The GPS orbits and the Earth's orientation pa- 


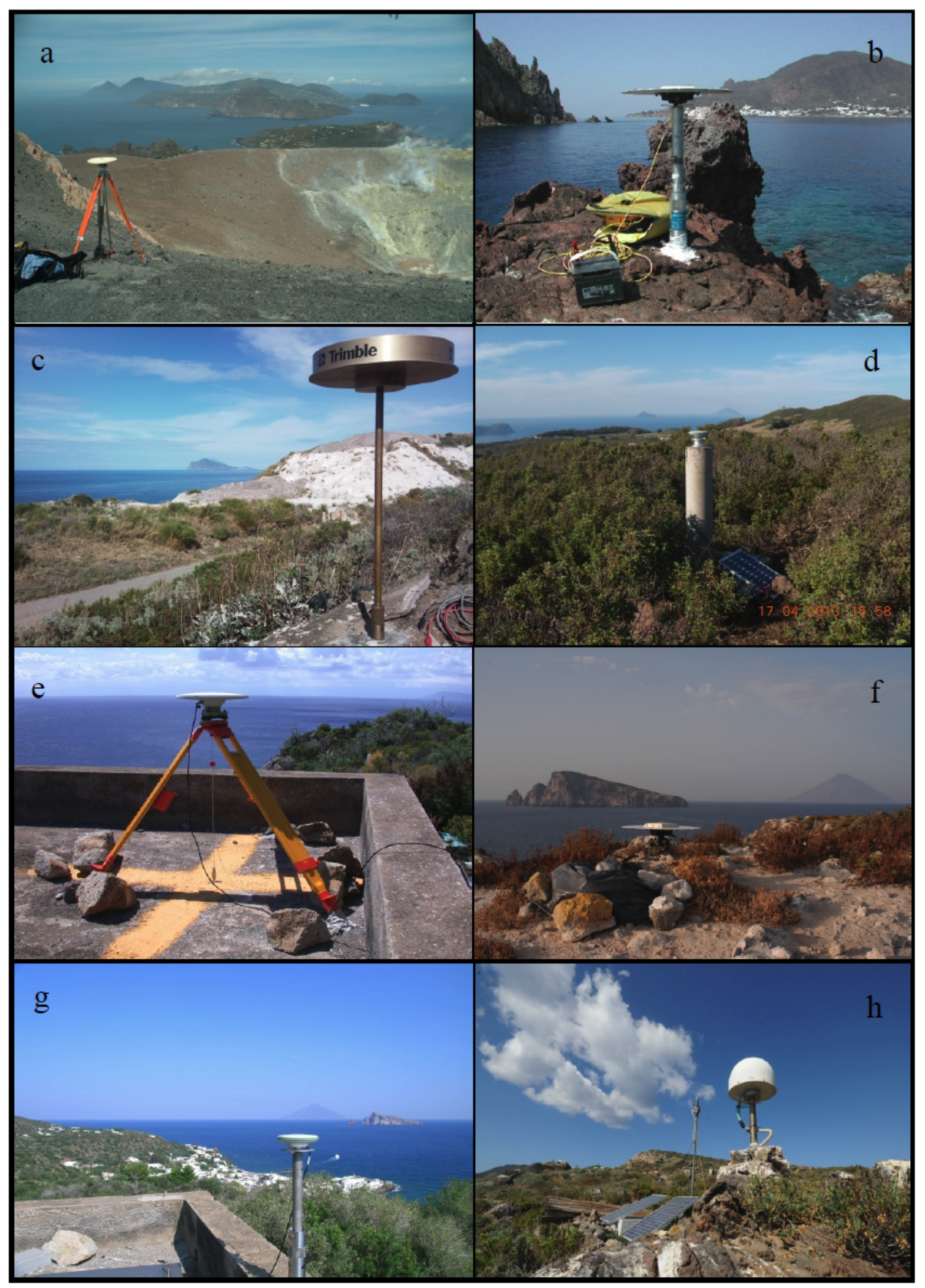

Figure 2. Typology of the GPS benchmarks: (a) iron spike fixed in rock outcrop, requiring tripod for antenna set up; (b) 3D iron made benchmark fixed in rocky outcrop. Antenna set up is constrained by the 3D monument (INGV type, Anzidei and Esposito [2003]); (c) Hungarian type bronze made pole installed on benchmark fixed in rocky outcrop. Antenna set up is 3D constrained (used by INGV Catania and the former International Institute of Volcanology); (d) pillar built on rocky outcrop, with thread on top; (e) iron spike fixed on stable building; (f) IGM marker fixed in rocky outcrop, with IGM base; (g) 3D benchmark on roof of stable building; (h) CGPS station (Lisca Bianca with 3D monument fixed on rocky outcrop).

rameters are fixed to the combined IGS products and an a priori loose constraint of $10 \mathrm{~m}$ is assigned to all site coordinates. The elevation-dependent phase center corrections and absolute phase center calibrations are applied. The troposphere modeling consists in an a priori
dry-Niell model fulfilled by the estimation of zenith delay corrections at 1-hour intervals at each site using the wet-Niell mapping function; in addition one horizontal gradient parameter per day at each site is estimated. The ionosphere is not modeled a priori, but it is 


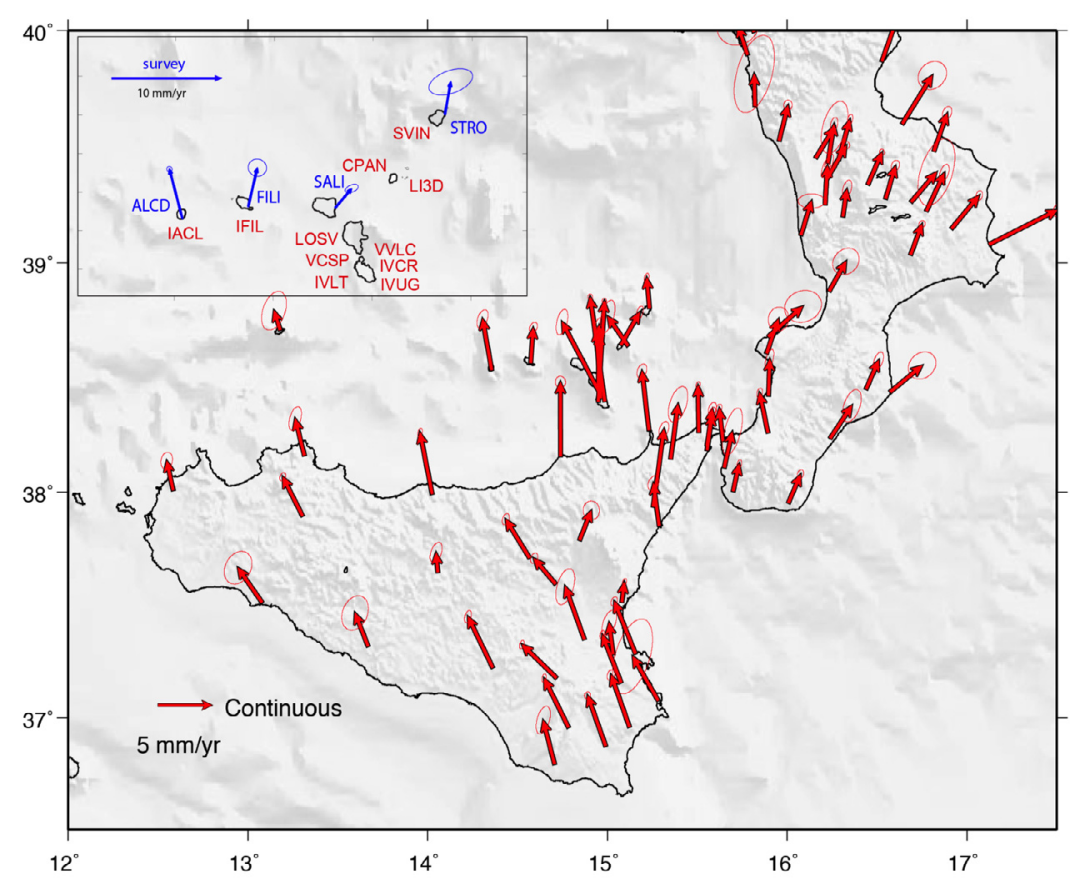

Figure 3. The geodetic velocity field for southern Italy, estimated from the CGPS regional network. In the inset are reported location and velocity of the CGPS (red arrows) and the regional survey style GPS stations (blue arrows) for the Aeolian Islands, analyzed in this paper. The closely spaced local networks at Lipari, Vulcano and Panarea are detailed in Figures 5 and 6.

removed by applying the ionosphere-free linear combination of L1 and L2 carriers. The ambiguity resolution is based on the QIF baseline-wise analysis. The final network solution is solved with back-substituted ambiguities, if integer; otherwise ambiguities are considered as real valued measurement biases.

Thus the daily GPS solutions are not estimated in a given a priori reference frame but computed in a loosely constrained reference frame. The coordinates are randomly translated or rotated from day-to-day and their covariance matrices have large errors (on the order of meters) as a consequence of the loose constraints applied to the a priori parameters.

\subsection{Combination of daily solutions and reference frame} definition

The daily "loose" coordinate solutions, with their complete covariance matrices, saved as SINEX files, are day by day merged with daily loose SINEX files of a global network of 60 IGS stations. Basically, the two sets of solutions share 9 common sites allowing the combination into a unique solution using a classical least-squares approach where the coordinates are both observations and estimated parameters [Devoti 2012].

After these combinations, to express the daily coordinates of the overall network in a unique reference

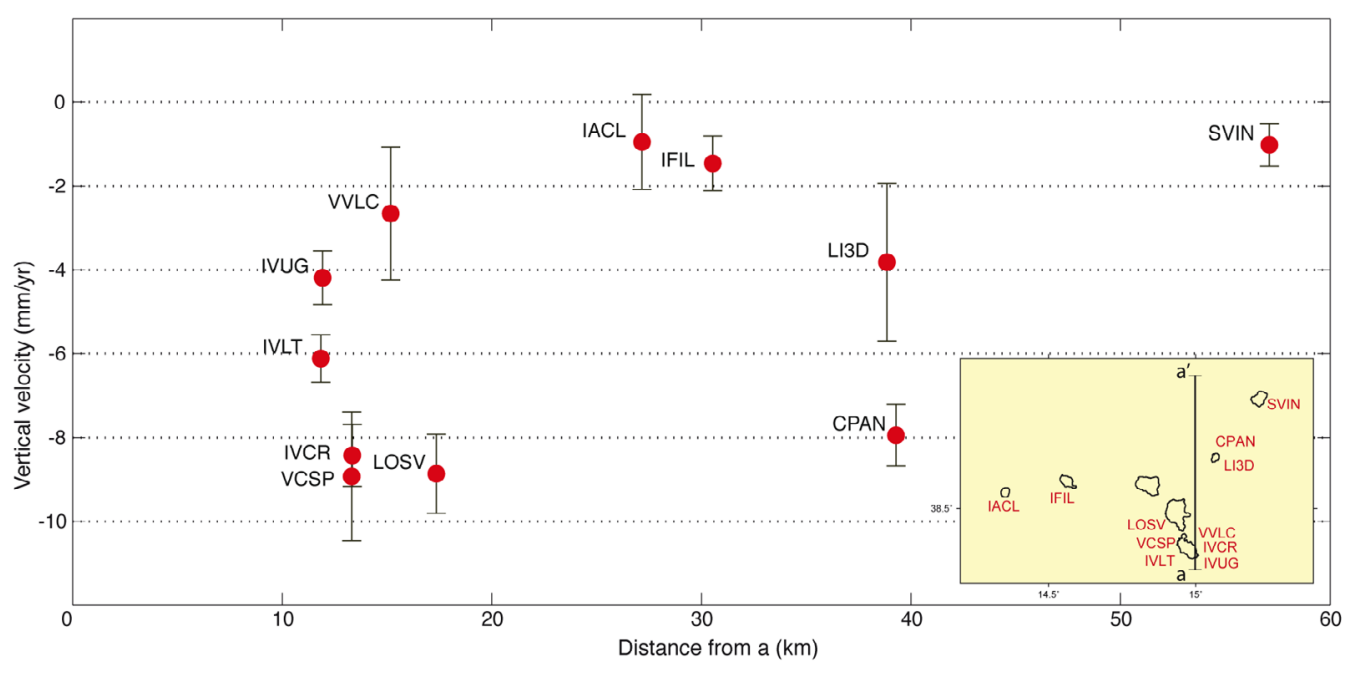

Figure 4. Geodetic vertical velocity for the Aeolian Islands from the CGPS network. 
frame and to compute the real covariance matrix, we perform two main transformations. First the loose covariance matrix is projected into a well-defined reference frame imposing tight internal constraints (at the millimeter level), and then coordinates are transformed into the ITRF2008 [Altamimi et al. 2007] by a 4-parameter Helmert transformation (translations plus scale factor); the proper set of constraints is driven by the rank deficiency of the normal matrices, a comprehensive discussion of the rank deficiency of our solutions is given in Devoti et al. [2010].

\subsection{Time series analysis and velocity field estimation}

Site velocities are estimated fitting simultaneously a linear drift, episodic offsets and annual sinusoids to all the coordinate time series. Offsets are estimated whenever a change in the GPS equipment induces a significant transient in the time series, whereas seasonal oscillations are accounted for by annual sinusoids. Outliers are rejected whenever the weighted residual exceeds three times the global chi square $\left(\chi^{2}\right)$.

At this stage we combine the obtained network velocity solution, expressed in the ITRF2008 reference frame, with an independent velocity solution of 171 GPS permanent sites in southern Italy in the time span
1998 to 2013 [Devoti et al. 2014]. Also this latter velocity field is referred to ITRF2008 frame and is derived from data of permanent GPS stations belonging to the RING network of INGV [Avallone et al. 2010], including also CGPS stations in the Aeolian Islands, and to other different networks in Italy.

The velocity combination procedure consists of a linear least-squares approach [Devoti 2012, Galvani et al. 2012, Devoti et al. 2015]. The normal matrix is formed from the two independent velocity solutions, and then it is inverted to estimate the unified velocity field of the entire network. As the covariance matrix is usually known separately from a constant multiplier, we also estimate a solution-scale factor together with the combined velocity solution. This ensures that the individual $\chi^{2}$ of each velocity solution is equally balanced (individual solutions do not prevail in the combination process) and the total $\chi^{2}$ is close to unity (realistic errors). The combined solution represents a weighted velocity average that takes into account the correlation matrices of the two solutions.

In the auxiliary material are included the plots of the time series for the north, east and up component of the motion for each benchmark obtained from our analyses.
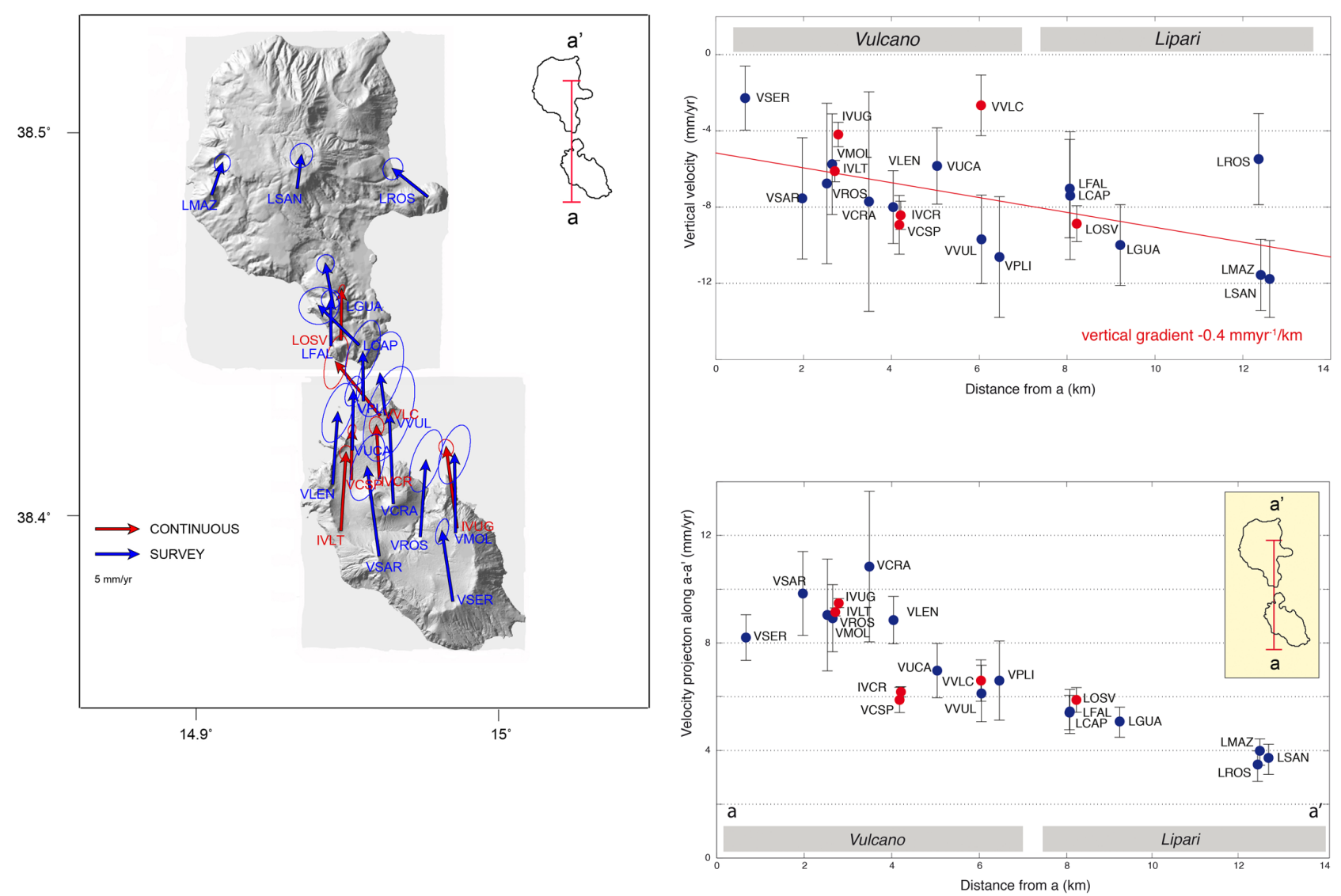

Figure 5. Left: the horizontal velocity field from the GPS survey style networks of Lipari-Vulcano; top right: GPS and CGPS horizontal velocities projected along cross section a-a'; bottom right: CGPS and GPS vertical velocities projected along a-a'. 

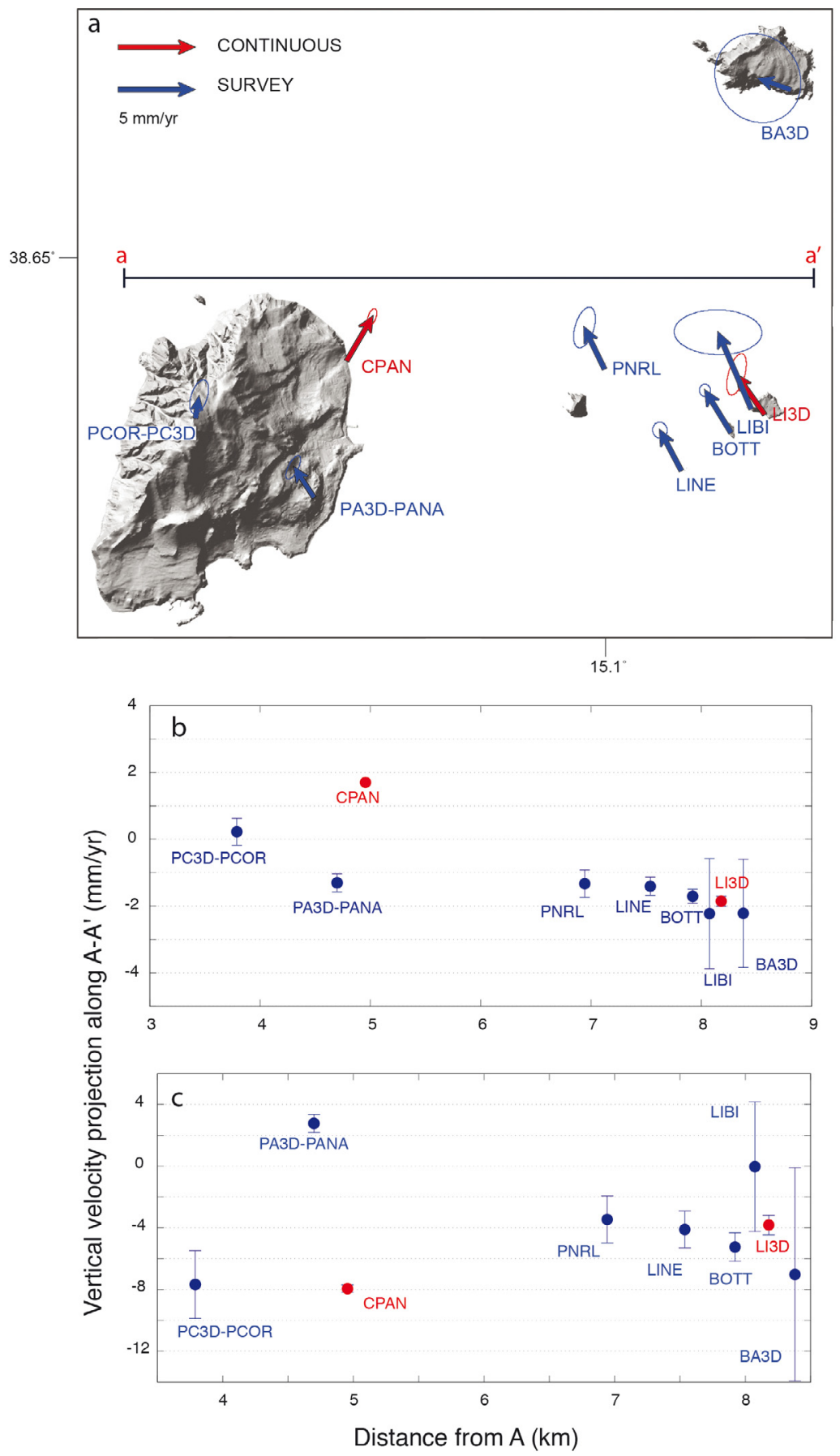

Figure 6. (a) the horizontal velocity field from the GPS survey style network of Panarea; (b) GPS and CGPS horizontal velocities projected along cross section a-a'; (c) CGPS and GPS vertical velocities projected along a-a'.

\section{Results}

The horizontal GPS velocity field at the regional scale of the Aeolian Islands, expressed with respect to a fixed Eurasian plate, shows a pattern characterized by lithospheric shortening from SE to NW, gradually decreasing from $\mathrm{S}$ to $\mathrm{N}$ (Figure 3, Table 2).

The CGPS stations provide horizontal velocities up to about $6 \mathrm{~mm} / \mathrm{yr}^{-1}$ (VCSP and IVCR, at Vulcano) (Figure 3), while vertical velocities show a diffuse subsidence up to about $-9 \mathrm{~mm} / \mathrm{yr}^{-1}$ (LOSV at Lipari and VCSP at Vulcano) (Figure 4).
GPS velocities estimated at the benchmarks of the discrete networks are up to $10.8 \mathrm{~mm} / \mathrm{yr}^{-1}$ (VCRA, at Vulcano) along the horizontal (Figure 3 ) and up to $-11.8 \mathrm{~mm} / \mathrm{yr}^{-1}$ (LSAN benchmark at Lipari) along the vertical, respectively (Figure 4).

The local GPS network of Lipari-Vulcano shows an overall northward trending of the ground motion with tiny rotations between NNE to NNW (Figure $5 \mathrm{a}, \mathrm{b})$. An active about N-S shortening with a maximum between la Fossa Caldera and Vulcanello is currently acting, as also reported in Bonforte and Guglielmino 
[2008]. Subsidence is up to $12 \mathrm{~mm} / \mathrm{yr}^{-1}$ with a gradient of $0.4 \mathrm{mmyr}^{-1} \mathrm{~km}^{-1}$, occurring in a narrow zone between Lipari and Vulcano (Figure 5c). It is worth noting that the increasing N-S subsidence is occurring with increasing N-S contraction. Maximum values have been estimated within the island of Vulcano.

The local GPS network of Panarea shows an overall shortening mainly located between the Islets (Lisca Bianca, Lisca Nera, Bottaro and I Panarelli) and the SE portion of Panarea Island and the NW sector of island along the structural lineaments NE-SW trending [Esposito et al. 2010] (Figure 6a,b). A general subsiding trend affects the Panarea network with values between -3 and $-9 \mathrm{~mm} /$ year (Figure $6 \mathrm{c}$ ), while a shortening at rates of $10^{-6}$ year $^{-1}$ has been estimated in the area surrounding the Islets.

\section{Discussion and conclusion}

We archived and analyzed GPS data collected in Aeolian archipelago in the last eighteen years from 1995 to 2013 , focusing on the discrete networks.

Although the CGPS networks provide continuous data to study the kinematics of this region, the dense local scale survey style GPS networks detail the deformation of local scale areas in such a complex and transitional region, at low costs and with high accuracy. Indeed, both data sets provide consistent values of horizontal and vertical velocities and are in agreement to show a subsiding behavior of this region.

The joint analysis of the regional and local networks, allowed estimating the velocity field at different spatial scales in this region. Results are in agreement with previous studies, highlighting and detailing the kinematics of local active areas, thanks to the high number of GPS benchmarks located in this region. Mainly, how the central Aeolian Island is the area of transition between the active N-S compression in the northwestern part of the archipelago and the NW-SE trending extension recognized in the eastern part of Aeolian arc, eastern Sicily and Calabria. In addition, the local networks analyzed in this paper, with their benchmarks distributed over a few $\mathrm{km}^{2}$ of land and closely spaced (even less than $1 \mathrm{~km}$ ), evidenced that the ground velocity field is affected by local disturbances and high gradient of deformations, related to the combination and superimposition of volcanic and tectonic signals within this region. Finally, our GPS data archive is freely accessible by anonymous ftp, to give new opportunities to the scientific community. We believe that data mining for this data set, even in combination with other independent data, can support further studies for the assessment of tectonic and volcanic hazard of this still active region.
Acknowledgements. We are thankful to all researchers and technicians of the INGV, Universities and Institutions that during the last twenty-five years contributed to the networks realization and field measurements. This study benefited from funding provided by the Italian Presidenza del Consiglio dei Ministri - Dipartimento della Protezione Civile (DPC), during the emergency Panarea-Stromboli 2002-2005 and in the frame of the project DPCINGV-V3 project 2012 Multi-disciplinary analysis of the relationships between tectonic structures and volcanic activity. We gratefully acknowledge the President of INGV, Prof. Stefano Gresta and the DPC Project coordinators Raffaele Azzaro and Rosanna De Rosa for insightful discussion and support. A special thanks to the Capitaneria di Porto of Lipari that supported surveys across the Aeolian Islands. Scientific papers funded by the DPC do not represent its official opinions and policies.

\section{References}

Achilli, V., M. Anzidei, P. Baldi, C. Gasparini, M. Marsella and F. Riguzzi (1993). Tyrgeonet: a global positioning system geodetic network for the geodynamical survey of the Italian peninsula, Annali di Geofisica, 36 (2), 191-200.

Alparone, S., A. Bonforte, S. Gambino, F. Guglielmino, F. Obrizzo and R. Velardita (2014). Dynamics of Vulcano Island Investigated by Long-Term (40 years) Geophysical Data, Miscellanea INGV, 25, Conferenza A. Rittmann, Nicolosi (Catania), ISSN 2039-6651.

Altamimi, Z., X. Collilieux, J. Legrand, B. Garayt and C. Boucher (2007). ITRF2005: A new release of the International Terrestrial Reference Frame based on time series of station positions and Earth Orientation Parameters, Journal of Geophysical Research, 112, B09401; doi:10.1029/2007JB004949.

Anzidei, M., P. Baldi, G. Casula, F. Riguzzi and L. Surace (1995). La rete Tyrgeonet, Supplemento al Bollettino di Geodesia e Scienze Affini, 54 (2), Istituto Geografico Militare, Firenze.

Anzidei, M., P. Baldi, C. Bonini, G. Casula, S. Gandolfi and F. Riguzzi (1998). Geodetic surveys across the Messina Straits (Sourthern Italy) seismogenic area, Journal of Geodynamics, 25 (1), 85-97.

Anzidei, M., P. Baldi, G. Casula, A. Galvani, E. Mantovani, A. Pesci, F. Riguzzi and E. Serpelloni (2001). Insights into present-day crustal motion in the central Mediterranean area from GPS surveys, Geophysical Journal International, 146, 98-110.

Anzidei, M., and A. Esposito (2003). Linee guida per la identificazione di siti idonei alla realizzazione di stazioni GPS permanenti e non permanenti, Rapporti Tecnici INGV, 18.

Anzidei, M., G. Casula, A. Galvani, F. Riguzzi, G. Pietrantonio, A. Massucci, S. Del Mese, F. Loddo, A. Pesci and A. Esposito (2004). Le prime stazioni GPS permanenti INGV-CNT per il monitoraggio delle deformazioni crostali dell'area italiana, Quaderni di Geofisica, 39. 
Anzidei, M., P. Baldi, A. Pesci, A. Esposito, A. Galvani, F. Loddo and P. Cristofoletti (2005). Geodetic deformation across the central Apennines from GPS data in the time span 1999-2003, Annals of Geophysics, 48 (2), 259-271.

Anzidei, M., P. Baldi and E. Serpelloni (2008). The coseismic ground deformations of the 1997 UmbriaMarche earthquakes: a lesson for the development of new GPS networks, Annals of Geophysics, 51 (2/3), 343-359.

Anzidei, M., E. Boschi, V. Cannelli, R. Devoti, A. Esposito, A. Galvani, D. Melini, G. Pietrantonio, F. Riguzzi, V. Sepe and E. Serpelloni (2009) Coseismic deformation of the destructive April 6, 2009 L'Aquila earthquake (central Italy) from GPS data, Geophysical Research Letters, 36, L17307; doi:10.1029/ 2009 GL039145.

Argnani, A., E. Serpelloni and C. Bonazzi (2007). Pattern of deformation around the central Aeolian Islands: evidence from multichannel seismics and GPS data, Terra Nova, 19, 317-323.

Avallone, A., G. Selvaggi, E. D’Anastasio, N. D’Agostino, G. Pietrantonio, F. Riguzzi, E. Serpelloni, M. Anzidei, G. Casula, G. Cecere, C. D’Ambrosio, P. De Martino, R. Devoti, L. Falco, M. Mattia, M. Rossi, F. Obrizzo, U. Tammaro and L. Zarrilli (2010). The RING network: improvement of a GPS velocity field in the central Mediterranean, Annals of Geophysics, 53 (2), 39-54.

Baldi, P., R. Devoti, F. Riguzzi and G. Pietrantonio (2015). Satellite positioning and geophysics studies in Italy, Rend. Fis. Accademia dei Lincei, 26, Suppl. 1, S33-S41.

Barberi F., P. Gasparini, F. Innocenti and L. Villari (1973). Volcanism of the southern Tyrrhenian Sea and its geodynamic implications, Journal of Geophysical Research, 78, 5221-5232.

Barreca, G., V. Bruno, F. Cultrera, M. Mattia, C. Monaco and L. Scarfi (2014). New insights in the geodynamics of the Lipari-Vulcano area (Aeolian Archipelago, southern Italy) from geological, geodeticand seismological data, Journal of Geodynamics, 82, 150-167.

Beccaluva, L., G. Gabbianelli, F. Lucchini, L. Rossi and C. Savelli (1985). Petrology and K/Ar ages of volcanic dredged from the Aeolian seamounts: implications for geodynamic eruption of the southern Tyrrhenian basin, Earth and Planetary Science Letters, 74, 187-208.

Bonaccorso, A. (2002). Ground deformation of the southern sector of the Aeolian Islands volcanic arc from geodetic data, Tectonophysics, 351, 181-192.

Bonaccorso, A., A. Bonforte and S. Gambino (2010).
Thermal expansion-contraction and slope instability of a fumarole field inferred from geodetic measurements at Vulcano, Bulletin of Volcanology, 72, 791-801; doi:10.1007/s00445-010-0366-7.

Bonforte, A., and F. Guglielmino (2008). Transpressive strain on the Lipari-Vulcano volcanic complex and dynamics of the "La Fossa" cone (Aeolian Islands, Sicily) revealed by GPS surveys on a dense network, Tectonophysics, 457, 64-70; doi:10.1016/j.tecto.2008. 05.016.

Chiarabba, C., P. De Gori and F. Speranza (2008). The southern Tyrrhenian subduction zone: Deep geometry, magmatism and Plio-Pleistocene evolution, Earth and Planetary Science Letters, 268, 408-423.

Dach, R., U. Hugentobler, P. Fridez and M. Meindl (2007). Bernese GPS Software version 5.0, Astronomical Institute, University of Bern, Switzerland.

D’Agostino, N., and G. Selvaggi (2004). Crustal motion along the Eurasia-Nubia plate-boundary in the Calabrian Arc and Sicily and active extension in the Messina Straits from GPS measurements, Journal of Geophysical Research, 109, B11402; doi:10.1029/20 04JB002998.

De Astis, G., G. Ventura and G. Vilardo (2003). Geodymamic significance of the Aeolian volcanism (southern Tyrrhenian Sea, Italy) in light of structural, seismological and geochemical data, Tectonics, 22, 1040; doi:10.1029/2003TC001506.

De Martino, P., U. Tammaro and F. Obrizzo (2014). GPS time series at Campi Flegrei caldera (2000-2013), Annals of Geophysics, 57 (2); doi:10.4401/ag-6431.

Devoti, R., G. Pietrantonio, A.R. Pisani, F. Riguzzi and E. Serpelloni (2010). Present day kinematics of Italy, In: M. Beltrando, A. Peccerillo, M. Mattei, S. Conticelli and C. Doglioni (eds.), Journal of the Virtual Explorer, 36, 2.

Devoti, R., A. Esposito, G. Pietrantonio, A.R. Pisani and F. Riguzzi (2011). Evidence of large scale deformation patterns from GPS data in the Italian subduction boundary, Earth Planetary Science Letters, 311 (3-4), 1-12; http:// dx.doi.org/10.1016/j.epsl.2011.09.034.

Devoti, R. (2012). Combination of coseismic displacement fields: a geodetic perspective, Annals of Geophysics, 55 (4); doi 10.4401/ag-6119.

Devoti, R., L. Anderlini, M. Anzidei, A. Esposito, A. Galvani, G. Pietrantonio, A.R. Pisani, F. Riguzzi, V. Sepe and E. Serpelloni (2012). The coseismic and postseismic deformation of the L'Aquila, 2009 earthquake from repeated GPS measurements, Italian Journal of Geosciences (Boll. Soc. Geol. It.), 131 (3), 348-358; doi:10.3301/IJG.2012.15.

Devoti, R., G. Pietrantonio and F. Riguzzi (2014). GNSS networks for geodynamics in Italy, Fisica de la 
Tierra, 26, 11-24.

Devoti, R., G. Pietrantonio, A.R. Pisani and F. Riguzzi (2015). Permanent GPS networks in Italy: analysis of time series noise, VIII Hotine Marussi Symposium, Roma.

Dvorak J., and D. Dzurisin (1997). Volcano geodesy: the search for magma reservoirs and the formation of eruptive vents, Review in Geophysics, 35, 343-384.

Esposito, E., M. Anzidei, S. Atzori, R. Devoti, G. Giordano and G. Pietrantonio (2010). Modeling ground deformations of Panarea volcano hydrothermal/geothermal system (Aeolian Islands, Italy) from GPS data, Bulletin of Volcanology; doi:10.1007/s00445010-0346-y.

Faccenna, C., T.W. Becker, F.P. Lucente, L. Jolivet and F. Rossetti (2001). History of subduction and back-arc extension in the central Mediterranean, Geophysical Journal International, 145, 809-820.

Ferranti, L., M. Palano, F. Cannavò, M.E. Mazzella, J.S. Oldow, E. Gueguen, M. Mattia and C. Monaco (2014). Rates of geodetic deformation across active faults in southern Italy, Tectonophysics, 621, 101122; doi:10.1016/j.tecto.2014.02.007.

Galvani, A., M. Anzidei, R. Devoti, A. Esposito, G. Pietrantonio, A.R. Pisani, F. Riguzzi and E. Serpelloni (2012). The interseismic velocity field of the central Apennine from a dense GPS network, Annals of Geophysics, 55 (5), 1039-1049; doi:10.4401/ ag-5634.

Hollenstein, C.H., H.G. Kahle, A. Geiger, S. Jenny, S. Goes and D. Giardini (2003). New GPS constraints on the Africa-Eurasia plate boundary zone in southern Italy, Geophysical Research Letters, 30 (18), 1935; doi:10.1029/2003GL017554.

Kaniuth, K., H. Tremel, Stuber, K., H. Drewes, S. Zerbini and P. Baldi (1989). Evaluation of the 1988 Tyrrhenian-Pelagian GPS campaing, Proceedings of the Fourth International Conference on the Wegener/Medlas project, Scheveningen.

Malinverno, A., and W.B.F. Ryan (1986). Extension in the Tyrrhenian Sea and shortening in the Apennines as result of arc migration driven by sinking of the lithosphere, Tectonics, 5, 227-245.

Mastrolembo Ventura, B., E. Serpelloni, A. Argnani, A. Bonforte, R. Bürgmann, M. Anzidei, P. Baldi and G. Puglisi (2014). Fast geodetic strain-rates in eastern Sicily (southern Italy): New insights into block tectonics and seismic potential in the area of the great 1693 earthquake, Earth and Planetary Science Letters, 404, 77-88.

Mattia, M., M. Palano, V. Bruno, F. Cannavò, A. Bonaccorso and S. Gresta (2008). Tectonic features of the Lipari-Vulcano complex (Aeolian archipelago, Italy) from 10 years (1996-2006) of GPS data, Terra Nova, 20, 370-377.

Neri, G., G. Barberi, B. Orecchio and A. Mostaccio (2003). Seismic strain and seismogenic stress regimes in the crust of the southern Tyrrhenian region, Earth and Planetary Science Letters, 213, 97-112.

Patanè, D., A. Aiuppa, M.Aloisi, B. Bencke, A. Cannata, M. Coltelli, G. Di Grazia, S. Gambino, S. Gurrieri, M. Mattia and G. Salerno (2013). Insights into magma and fluid transfer at Mount Etna by a multiparametric approach: A model of the events leading to the 2011 eruptive cycle, Journal of Geophysical Research: Solid Earth, 118 (7).

Pesci, A., G. Teza, G. Casula, M. Fabris and A. Bonforte (2013). Remote Sensing and Geodetic Measurements for Volcanic Slope Monitoring: Surface Variations Measured at Northern Flank of La Fossa Cone (Vulcano Island, Italy), Remote Sensing, 5, 2238-2256; doi:10.3390/rs5052238.

Pondrelli, S., C., Piromallo and E. Serpelloni (2004). Convergence vs. retreat in southern Tyrrhenian Sea: insights from kinematics, Geophysical Research Letters, 31, L06611; doi:10.1029/2003GL019223.

Selvaggi, G., M. Mattia, A. Avallone, N. D’Agostino, L. Abruzzese, M. Anzidei, M. Cantarero, V. Cardinale, A. Castagnozzi, G. Casula, G. Cerere, R. Cogliano, F. Criscuoli, C. D’Ambrosio, E. D’Anastasio, P. De Martino, S. Del Mese, G. De Luca and R. Devoti (2006). La Rete Integrata Nazionale GPS (RING) dell'INGV: una infrastruttura aperta per la ricerca scientifica, X Conferenza nazionale dell'ASITA, Bolzano (Italy), Atti, II, 1749-1754.

Serpelloni, E., M. Anzidei, P. Baldi, G. Casula and A. Galvani (2005). Crustal velocity and strain-rate fields in Italy and surrounding regions: new results from the analysis of permanent and non-permanent GPS networks, Geophysical Journal International, 161, 861-880; doi:10.1111/j.1365-246X.2005.02618.x.

Serpelloni, E., M. Anzidei, P. Baldi, G. Casula and A. Galvani (2006). GPS measurements of active strain across the Apennines, Annals of Geophysics, 49 (1), 319-329.

Serpelloni, E., G. Vannucci, S. Pondrelli, A. Argnani, G. Casula, M. Anzidei, P. Baldi and P. Gasperini (2007). Kinematics of the western Africa-Eurasia plate boundary from focal mechanisms and GPS data, Geophysical Journal International, 169, 1180-1200.

Serpelloni, E., R. Bürgmann, M. Anzidei, P. Baldi, B. Mastrolembo Ventura and E. Boschi (2010). Strain accumulation across the Messina Straits and kinematics of Sicily and Calabria from GPS data and dislocation modeling, Earth and Planetary Science Letters, 298, 347-360. 
Surace, L. (1997). La nuova rete geodetica nazionale IGM95: risultati e prospettive di utilizzazione, Bollettino di Geodesia e Scienze Affini, 3, 335-377.

Tregoning, P., and C. Rizos (2008). Science and Business Media. Springer, 936 pp.

\section{Supplementary material}

The following material annexed to the present publication is retrievable via anonymous FTP from: $\mathrm{ftp}$ / / ftp.ingv.it/pub/ainet-gpsdata 1 - Rinex data (ASCII files of GPS observations).

2 - Log files (ASCII files containing site information). 3 - Plot of the time series of N, E, UP components for AINET sites.

4 - Benchmarks occupation table (occupation history at the GPS benchmarks).

Corresponding author: Marco Anzidei,

Istituto Nazionale di Geofisica e Vulcanologia, Centro Nazionale Terremoti, Rome, Italy; email: marco.anzidei@ingv.it.

(C) 2015 by the Istituto Nazionale di Geofisica e Vulcanologia. All rights reserved. 